\title{
Silanol - A novel class of antimicrobial agent
}

\author{
Yun-mi Kim \\ Department of Materials Science and Engineering \\ University of Florida \\ Gainesville, FL 32611, USA \\ Tel: 13528463793 \\ Fax: 13528463355 \\ E-mail: yunmi740@ufl.edu \\ Samuel Farrah \\ Department of Microbiology and Cell Science \\ University of Florida \\ Gainesville, FL 32611, USA \\ Tel: 13523925925 \\ Fax: 1-352 3925922 \\ E-mail: sfarrah@ufl.edu \\ Ronald H. Baney* \\ Department of Materials Science and Engineering \\ University of Florida \\ Gainesville, FL 32611, USA \\ Tel: 13528463785 \\ Fax: 13528463355 \\ E-mail: rbane@mse.ufl.edu
}

Financial support: Air force Research Lab.

Keywords: antimicrobial agents, bacteria, biocide, silanols.

Abbreviations: cfu: Colony Forming Units.

MLC: Minimum Lethal Concentration.

Recently, a significant amount of attention has been directed toward development of novel classes of biocides because of the potential for microbial contamination and infection risks to military personnel and in the general population. We have recently discovered a new and unexpected class of powerful biocides based upon compounds derived through simple chemistry from silicone intermediates, "silicon alcohols" called, silanols. One example is trialkylsilanols, $\mathrm{R}_{3} \mathrm{SiOH}$. Antimicrobial tests were carried out against Gram-negative bacterium, Escherichia coli, and Gram-positive, Staphylococcus aureus, with silanols, t-butanol, and siloxanes. Trialkylsilanols were very effective biocides against Escherichia coli and Staphylococcus aureus. The number of viable bacteria reduced was more than eight orders of magnitude with silanol treatments. Triethylsilanol, in particular, exhibited a strong antimicrobial effect at a very low concentration within 10 min. These novel biocide silanols can be prepared from low cost intermediates derived from the commercial processesassociated with the silicone industry. Silanols are considered environmentally benign because of their transitory nature and ultimate conversion to $\mathrm{CO}_{2}, \mathrm{SiO}_{2}$, and $\mathrm{H}_{2} \mathrm{O}$.
Various types of biocides are used in antiseptics and disinfectants to inhibit or destroy selective bacteria or other microorganisms (McDonnell and Russell, 1999). On the basis of their activity against microbes, antimicrobial agents can be classified into two groups, bacterialcidal and sporocidal. Quaternary ammonium compounds and alcohols are frequently used as bacterialcidal. Peracetic acid, glutaraldehyde, and chlorine-releasing agents show both bacterialcidal and sporocidal activity, although a much higher concentration is needed to achieve the sporocidal effect due to the high resistance of spores. Chlorine dioxide was recently used for decontamination of Bacillus anthracis by Bio.ONE ${ }^{\mathrm{TM}}$, Sabre/Giuliani Company, however, concerns were raised due to its highly toxic and corrosive properties.

We have recently discovered a new class of strong biocides called silanols, demonstrated an enhanced antimicrobial activity compared to the analogous organic alcohols. Organosilicon compounds showed a greater hydrophobicity than organic compounds due to low group rotational energy (Owen, 1990) and silanols demonstrated a greater acidity compared to the corresponding organic alcohols because of electron back donation from oxygen through $(\mathrm{p} \rightarrow \mathrm{d}$

* Corresponding author 
orbital) $\pi$ bond (West and Baney, 1959). We hypothesized that these unique properties of organosilicon compounds such as silanols may enhance the antimicrobial activity of silanols. Although a mechanism of the antimicrobial effect of silanols has not yet been clearly determined. Antimicrobial tests involving a wide range of microorganisms and fundamental studies to understand the mechanism of the bioactivity are currently underway. Silanols can be applied by a various delivery systems such as a neat liquid phase, vapor phase due to their high volatility, and as bound antimicrobial agents.<smiles>CC(C)(C)O</smiles>

a)<smiles>C[Si](C)(C)O</smiles>

b)
Figure 1. Chemical structures of :

a) $t$-butanol

b) Trimethylsilanol.

There is a significant amount of evidence that suggests possible interactions between silicon compound and biological systems. It has been known for several years that silicone elastomers exhibits excellent marine fouling release properties (Stein et al. 2003a; Stein et al. 2003b). The antifouling effect of silicone elastomers suggests that there could be a specific interaction between silicone and microorganisms preventing silicone surface from accumulating microorganisms. Toxicity research of silicones was reported several years ago (Bennett and Staratt, 1973) in a short abstract. Trimethylsilanol, a potential end group hydrolysis product of linear polydimethylsiloxane, had been evaluated toxicologically by testing on mouse, rat, rabbit, and monkey models (Bennett and Staratt, 1973). These authors claimed that trimethylsilanol was about three times as potent as $t$-butanol on an equimolar basis. Chemical structure of $t$-butanol is analogous to trimethylsilanol but central atom is silicon as shown Figure 1.

The environmental fate of silicones has been recently reviewed (Graiver et al. 2003). The hydrolysis of polydimethylsiloxane elastomer occurs in aqueous environments to generate cyclic volatile methyl siloxane such as octamethylcyclotetrasiloxane, and further degrades into dimethylsilanediol and trimethylsilanol, ultimately oxidize to environmentally benign silica, carbon dioxide and water in the environment. Graiver et al. 2003 suggested that the silicone compounds are environmentally friendly materials since the degradation process occurs in a short period and generates benign materials.

Trimethylsilanol, triethylsilanol and t-butanol were tested against Escherichia coli (E. coli) and Staphylococcus aureus (Staph. aureus) to estimate their relative antimicrobial activities. Octamethylcyclotetrasiloxane and siloxanes formed by the condensation of the silanols were also evaluated.

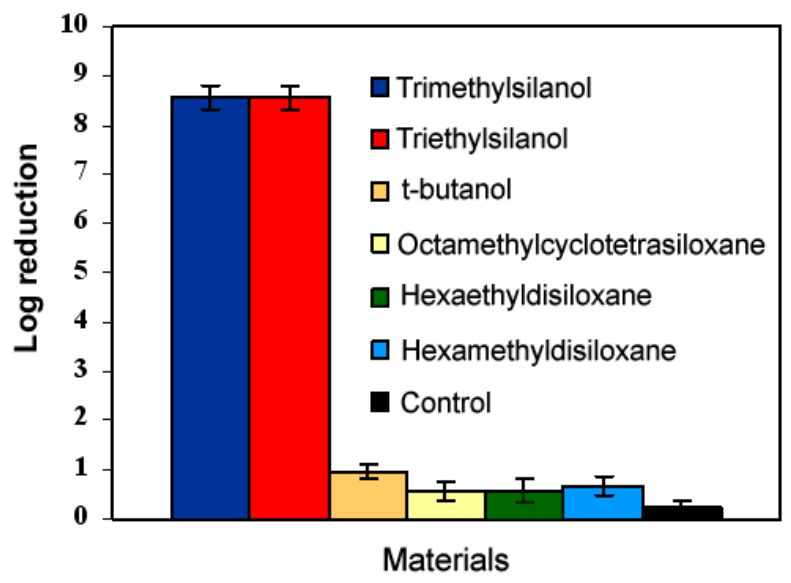

Figure 2. Antimicrobial test with E. coli at $10 \% \mathrm{~g} / \mathrm{g}$ of materials.

\section{MATERIALS AND METHODS}

The trialkylsilanols were prepared by the hydrolysis of their organosilicon halide precursors by a method similar to Kantor (Sauer, 1944; Kantor, 1953). Organosilicon halides and water were mixed for $15 \mathrm{~min}$ in diethyl ether solution with ammonium hydroxide as a catalyst. The silanol content of trimethylsilanol measured by ${ }^{29} \mathrm{Si}$ and ${ }^{1} \mathrm{H}$ NMR (Nuclear Magnetic Resonance spectroscopy) method was $95 \pm 3 \%$. The impurity of trimethylsilanol was identified as hexamethyldisiloxane. Triethylsilanol obtained from Gelest Inc. was used as received and the measured silanol content was $95 \pm 3 \%$. The impurity of triethylsilanol was hexaethyldisiloxane. $t$-butanol was obtained from Acros organics and octamethylcyclotetrasiloxane, hexamethyldisiloxane, and hexaethyldisiloxane were acquired from Gelest Inc.

The bacterial strains employed were E. coli C3000 (ATCC 15597) and Staph. aureus laboratory strain. E. coli and Staph. aureus suspension were prepared according to the procedure of Rincón (Rincón and Pulgarin, 2003). The bacteria were inoculated in Columbia broth overnight at $37^{\circ} \mathrm{C}$ with constant agitation under aerobic conditions. The bacterial cells were collected by centrifugation at $500 \mathrm{rcf}$ (relative centrifugal force) for $10 \mathrm{~min}$ at $4^{\circ} \mathrm{C}$ and washed three times with sterilized distilled water. A bacterial pellet was resuspended in the sterilized water after final washing. The concentration of E. coil and Staph. aureus was 2-6 x $10^{8} \mathrm{cfu} / \mathrm{ml}$ (colony forming units).

The antimicrobial test of the materials were carried out by adding a given amount of antimicrobial agent into $10 \mathrm{~g}$ of aqueous solution that contains the bacteria at a 
concentration of $2-6 \times 10^{8} \mathrm{cfu} / \mathrm{ml}$. The solution was mixed for an hour by stirring. Samples were diluted by a phosphate buffered saline and then plated on plate-count agar (Difco) (Collins et al. 1995). After 24 hrs incubation at $37^{\circ} \mathrm{C}$ the colonies that grew on the medium were counted in order to estimate the number of viable bacterial. Error bars in the figures were determined by taking the mean of 3-5 tests.

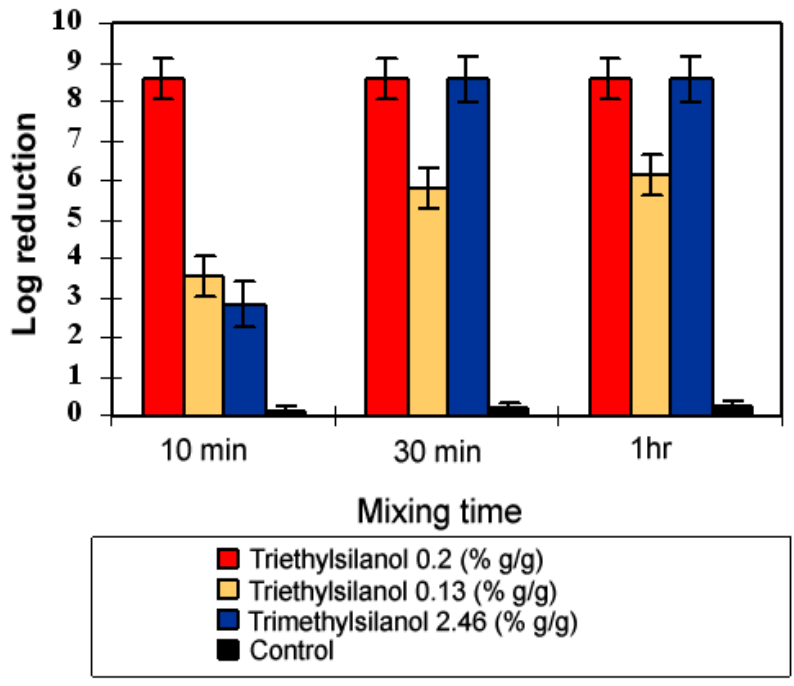

Figure 3. Antimicrobial test results with E. coli - concentration and mixing time dependent test.

\section{RESULTS AND DISCUSSION}

The antimicrobial tests were performed in aqueous solution by the procedure described above. Silanols, $t$-butanol, and siloxanes were evaluated against E. coli and Staph. aureus. Trimethylsilanol and triethylsilanol showed a strong bioactivity of more than an eight log reduction against $E$. coli, whereas t-butanol, octamethylcyclotetrasiloxane, hexamethyldisiloxane, and hexaethyldisiloxane showed little or no toxicity even at the high concentration of $10 \%$ $\mathrm{g} / \mathrm{g}$ as shown in Figure 2. Log reduction stands for a 10-fold or $90 \%$ reduction in numbers of bacteria. The different antimicrobial effects observed between trimethylsilanol and $t$-butanol demonstrates that the silanol can enhance biocidal properties against $E$. coli more effectively than the analogous organic alcohol. The results are consistent with the earlier toxicity research reported that trimethylsilanol was three times more potent than $t$-butanol (Bennett and Staratt, 1973).

We speculated that the greater acidity of silanols in comparison to analogous carbinols (West and Baney, 1959) and the higher hydrophobicity (Owen, 1990) of organosilicon compounds may explain the higher antimicrobial activities of silanols against E. coli and Staph. aureus. West and Baney showed that H-bond acidity of trimethylsilanol was two times higher than $t$-butanol (West and Baney, 1959). The hydrophobicity of the silanols and the alcohols was estimated by using the partition coefficient calculated by the Atom/Fragment Contribution method (Meylan and Howard, 1995).The partition coefficient of trimethylsilanol calculated was 1.14 , whereas that of $t$ butanol was 0.73.Hexamethyldisiloxane and hexaethyldisiloxane were tested because they can be formed by the condensation of the silanols in water and were identified as an impurity of trimethylsilanol and triethylsilanol respectively. The siloxanes showed a very low antimicrobial activity against $E$. coli compared to that of the silanols as demonstrated in Figure 2, illustrating that the silanols were responsible for the antimicrobial effects.

Further antimicrobial tests were carried out with respect to concentration of silanols and mixing time as shown in Figure 3. An increase of concentration of silanols improved the antimicrobial activities and reduced the time for inactivation of $E$. coli. Triethylsilanol exhibited more than 8 $\log$ reduction at concentration of $0.2 \% \mathrm{~g} / \mathrm{g}$ in a $10 \mathrm{~min}$ mixing. E. coli was more susceptible to triethylsilanol than trimethylsilanol. Trimethylsilanol required a longer time (30 $\mathrm{min}$ ) and a higher concentration of $2.46 \% \mathrm{~g} / \mathrm{g}$ to achieve a similar $8 \log$ reduction. The partition coefficient of triethylsilanol is 2.62, while that of trimethylsilanol is 1.14. However, the H-bond acidity of triethylsilanol was very similar to that of trimethylsilanol (West and Baney, 1959). It is possible that triethylsilanol showed a stronger antimicrobial activity due to the higher lipophilic nature.

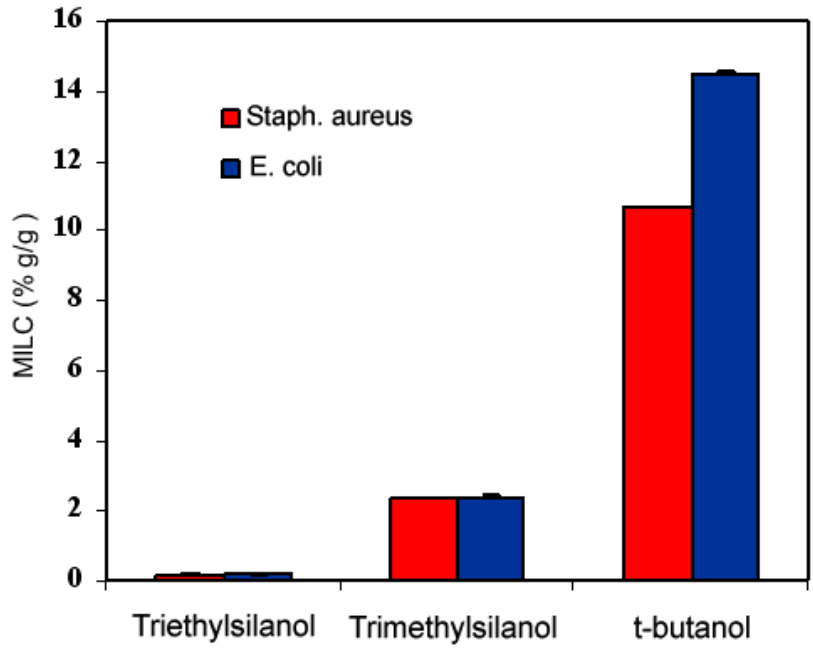

Figure 4. Minimum lethal concentration against E. coli and Staph. aureus.

The minimum lethal concentration (MLC) defined as the maximum dilution of the product that kills a test organism was determined. E. coli and Staph. aureus were treated with the silanols and $t$-butanol for an hour and the MLCs were obtained as shown Figure 4. The results showed that silanols were capable of deactivation of E. coli and Staph. aureus and were more effective antimicrobial agents than analogous alcohol.

Antimicrobial tests using a cosolvent such as propylene 
glycol n-propyl ether against $E$. coli were carried out to improve the antimicrobial effect and solubility of the silanols. Silanols mixed with the cosolvent exhibited a lower MLC compared to the experiments without cosolvent indicating an enhanced antimicrobial effect with the cosolvent as shown Figure 5. A control test consisting of water and $4.4 \% \mathrm{~g} / \mathrm{g}$ of the cosolvent without silanols showed less than one log reduction. Therefore, it is reasonable to speculate that improved antimicrobial activities of silanols with the cosolvent may be induced by enhanced solubility.

In summary, we do not fully understand the mechanism of the bioactivity of silanols. However, we found that the silanols were stronger antimicrobial agent against $E$. coli and Staph. aureus than the analogous alcohol such as $t$ butanol. The trialkylsilanols, $\mathrm{R}_{3} \mathrm{SiOH}$, containing different $\mathrm{R}$ exhibited a different degree of bioactivity suggesting that chemical structure is correlated to the bioactivity of silanols. Using proper cosolvent such as propylene glycol n-propyl ether can improve the bioactivity significantly. Mechanism studies are currently underway to determine the major antimicrobial mechanistic features of silanols.

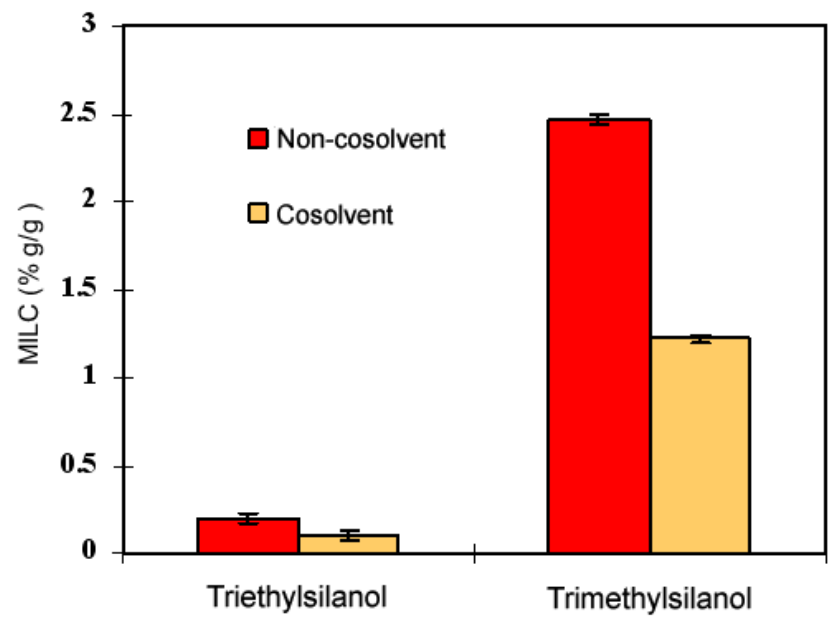

Figure 5. Minimum lethal concentration (MLC) of silanols against E. coli with or without cosolvent.

Non-cosolvent: water and silanols at a given concentration; Cosolvent: water, silanols, and propylene glycol n-propyl ether of $4.4 \% \mathrm{~g} / \mathrm{g}$.

\section{ACKNOWLEDGMENTS}

We are grateful to Dr. Ben Koopman for his generous support and Vijay Krishna for the training and helpful comments.

\section{REFERENCES}

BENNETT, D.R. and STARATT, W.H. Primate absorption and elimination balance studies including pulmonary, urinary, biliary and fecal excretion of t-butanol, trimethylsilanol, dimethylsilanediol and hexamethyldisiloxane. Toxicology and Applied Pharmacology, 1973, vol. 25, no. 3, p. 445.

COLLINS, C.H.; LYNE, P.M. and GRANGE, J.M. Microbiological Methods, $7^{\text {th }}$ edition: ButterworthHeinemann Ltd., 1995, 512 p. ISBN 0750606533.

GRAIVER, D.; FARMINER, K.W. and NARAYAN, R. A review of the fate and effects of silicones in the environment. Journal of Polymers and the Environment, October 2003, vol. 11, no. 4, p. 129-136.

KANTOR, S.W. The hydrolysis of methoxysilanesdimethylsilanediol. Journal of the American Chemical Society, 1953, vol. 75, no. 11, p. 2712-2714.

MCDONNELL, Gerald and RUSSELL, A. Denver. Antiseptics and disinfectants: Activity, action, and resistance. Clinical Microbiology Reviews, January 1999, vol. 12 , no. 1, p. 147-179.

MEYLAN, W.M. and HOWARD, P.H. Atom/fragment contribution method for estimating octanol-water partition coefficients. Journal of Pharmaceutical Sciences, January 1995 , vol. 84 , no. 1 , p. 83-92.

OWEN, M.J. Siloxane surface-activity. Advances in Chemistry Series, 1990, vol. 224, p. 705-739.

RINCÓN, A.G. and PULGARIN, C. Photocatalytical inactivation of $E$. coli: effect of (continuous-intermittent) light intensity and of (suspended-fixed) $\mathrm{TiO} 2$ concentration. Applied Catalysis B: Environmental, August 2003, vol. 44, no. 3, p. 263-284.

SAUER, R.O. Derivatives of the methylchlorosilanes. I trimethylsilanol and its simple ethers. Journal of the American Chemical Society, 1944, vol. 66, no. 10, p. 17071710.

STEIN, J.; TRUBY, K.; WOOD, C.D.; GARDNER, M.; SWAIN, G.; KAVANAGH, C.; KOVACH, B.; SCHULTZ, M.; WIEBE, D.; HOLM, E.; MONTEMARANO, J.; WENDT, D.; SMITH, C. and MEYER, A. Silicone foul release coatings: Effect of the interaction of oil and coating functionalities on the magnitude of macrofouling attachment strengths. Biofouling, April 2003, vol. 19, suppl. 1, p. 71-82.

STEIN, Judith; TRUBY, Kathryn; WOOD, Christina Darkangelo; TAKEMORI, Michael; VALLANCE, Michael; SWAIN, Geoffrey; KAVANAGH, Christopher; KOVACH, Brett; SCHULTZ, Michael; WIEBE, Deborah; HOLM, Eric; MONTEMARANO, Jean; WENDT, Dean; SMITH, Celia and MEYER, Anne. Structure-property relationships of silicone biofouling-release coatings: Effect of silicone network architecture on pseudobarnacle attachment strengths. Biofouling, April 2003, vol. 19, no. 2, p. 87-94. 
WEST, R. and BANEY, R.H. Hydrogen Bonding Studies 2.

The acidity and basicity of silanols compared to alcohols.

Journal of the American Chemical Society, 1959, vol. 81, no. 23 , p. $6145-6148$. 